\title{
Probabilistic ranking of power system loads for voltage stability studies in networks with renewable generation
}

DOI:

10.1109/ISGTEurope.2016.7856274

\section{Document Version}

Accepted author manuscript

Link to publication record in Manchester Research Explorer

\section{Citation for published version (APA):}

Zhu, Y., Qi, B., \& Milanovic, J. V. (2017). Probabilistic ranking of power system loads for voltage stability studies in networks with renewable generation. In PES Innovative Smart Grid Technologies Conference Europe (ISGTEurope), 2016 IEEE https://doi.org/10.1109/ISGTEurope.2016.7856274

\section{Published in:}

PES Innovative Smart Grid Technologies Conference Europe (ISGT-Europe), 2016 IEEE

\section{Citing this paper}

Please note that where the full-text provided on Manchester Research Explorer is the Author Accepted Manuscript or Proof version this may differ from the final Published version. If citing, it is advised that you check and use the publisher's definitive version.

\section{General rights}

Copyright and moral rights for the publications made accessible in the Research Explorer are retained by the authors and/or other copyright owners and it is a condition of accessing publications that users recognise and abide by the legal requirements associated with these rights.

\section{Takedown policy}

If you believe that this document breaches copyright please refer to the University of Manchester's Takedown Procedures [http://man.ac.uk/04Y6Bo] or contact uml.scholarlycommunications@manchester.ac.uk providing relevant details, so we can investigate your claim.

\section{OPEN ACCESS}




\title{
Probabilistic ranking of power system loads for voltage stability studies in networks with renewable generation
}

\author{
Yue Zhu, Buyang Qi, Student Member, IEEE, and Jovica V. Milanović, Fellow, IEEE
}

\begin{abstract}
Power system voltage stability is a crucial aspect of power system study, and loads have a significant influence on it. This paper uses PV curves to rank the power system loads according to their influence on the voltage stability. The Monte Carlo simulation is used to generate uncertainties to reflect the stochastic behaviour of power systems. The ranking order is acquired after considering different loading conditions obtained from the annual loading curve. The distribution of critical points on the 'PV nose curve' for the most important loads and least important loads in the network are used to verify the ranking. Different load models are applied to investigate the effect of load models on the critical point positions. The results show that load models have significant influence on the voltage collapse point.
\end{abstract}

Index Terms-- voltage stability, probability, load model, load ranking, Monte Carlo

\section{INTRODUCTION}

Power system voltage stability is an area that attracts a lot of research efforts because many power system failures have been caused by voltage instability [1-4]. The increasing loading has driven the power system to operate closer to the boundary of stability, which will significantly increase the risk of voltage collapse. Power system voltage instability is caused by increasing power demand, system disturbance, or shift of operating conditions, which leads to uncontrollable voltage drop [5]. Due to the previous reasons, keeping the voltage stability is essential, for power system operations and design.

To assess the proximity to voltage collapse, the voltage stability index plays a vital role. Power system operators apply these indices to decide whether the system faces the danger of voltage instability. The PV curve is a reliable and precise way to find the load margin. It calculates the power flow while increasing the load until the there is no solution for power flow equations [6-8]. The PV curve describes the voltage (V) at a bus against the total or bus loading $(\mathrm{P})$. The critical point of the PV curve corresponds to the last point before reaching the voltage stability limit [9]. The PV margin is the difference between the power at initial operating point and the critical point. It indicates how close the system is to the voltage collapse point.

This work was supported by the Research Councils UK, through the HubNet consortium (grant number: EP/I013636/1).

The authors are with the School of Electrical and Electronic Engineering, The University of Manchester, PO Box 88, Manchester, M60 1QD, UK. (email:yue.zhu-5@postgrad.manchester.ac.uk,milanovic@manchester.ac.uk).
The calculation of the PV curve relies on the existence of real solutions of the power flow. The accurate operating condition of the system, in particular system with renewable generation, is often difficult to model due to the random behaviour of the renewable generation, load variation, and component availability. Therefore, it is crucial that the voltage stability studies should involve the uncertainties associated with the stochastic nature of power system operating states. For the above reasons, the probabilistic method is more reliable than the deterministic method. The probabilistic assessment has the merit of combining the severity and the likelihood of an event to accurately represent the risks of system failure [10, 11]. A lot of research efforts have been placed on the probabilistic assessment of voltage stability, and many papers have been published as a result [12-15].

One of the major sources of power system uncertainty affecting the voltage stability is the uncertainty of power system load parameters. The modelling of power system components has a remarkable influence on voltage stability assessment, and load models in particular [16]. If the load model is not accurate, the power system may operate under a condition that leads to voltage instability [17]. A simple load model may not be able to reproduce the power system operating mode when conducting a simulation after a system collapse event [18]. Therefore, it is crucial to develop accurate load models for voltage stability studies.

It is very time consuming and costly, however, to model all of the loads in the power system accurately [19]. Distribution companies may not be able to provide enough funds and human resources to achieve such a goal. Besides, not all loads have the same influence on the voltage stability. Thus, a more cost effective approach is to identify the loads that need to be modelled accurately first and then other less important loads only require simple load models. In this way, there can be a significant saving in funds and human resources while to achieving the same accuracy of system studies.

This paper first applies the Monte Carlo (MC) method to simulate the effects of uncertainties on power system voltage stability. The uncertainties in load variation, and renewable generation are simulated first considering the rated system loading. The total loading is then increased until the critical point on PV curve is reached. Each load is ranked according to the average value of voltage difference between the critical point and the initial operating point, and the one having the largest difference is designated as the most important load. 


\section{ACCEPTED VERSION OF THE PAPER}

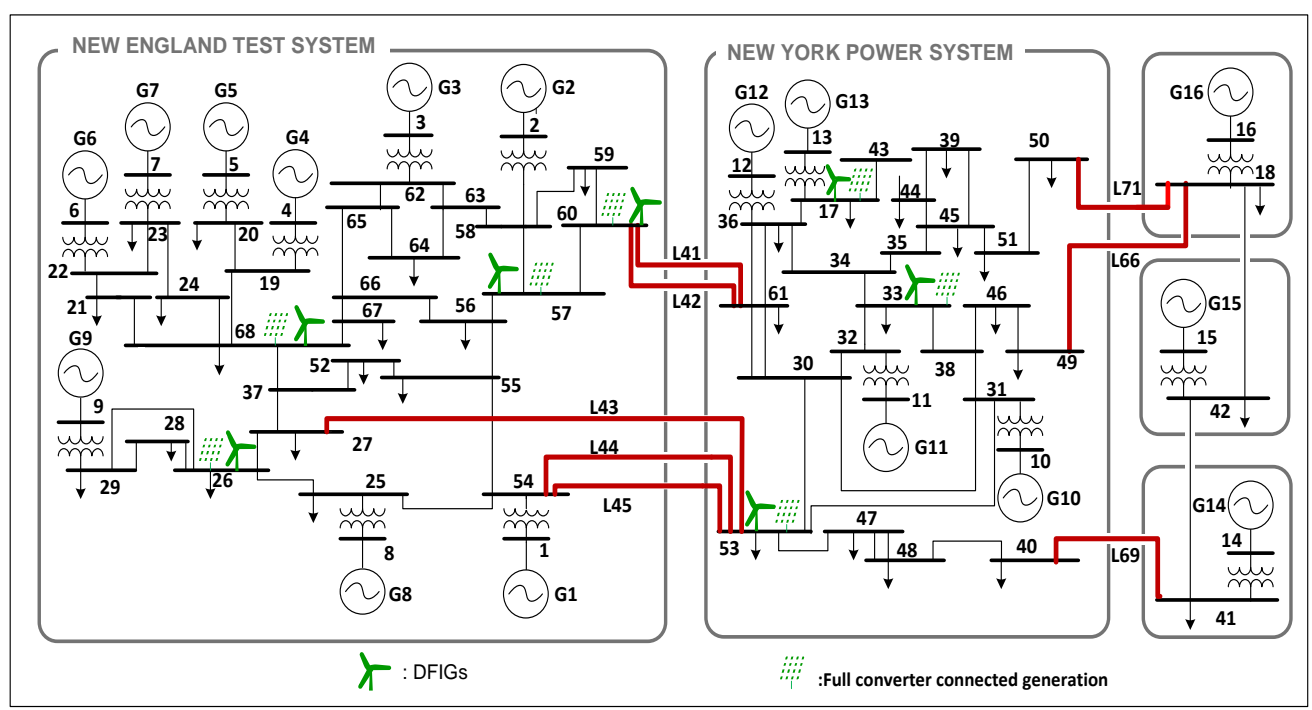

Fig. 1. The NETS-NYPS test system.

The five most important loads and five least important loads are identified first and further studies are carried out only using these loads. Different initial loading conditions are selected from the annual loading curve, and corresponding uncertainties modelled for each loading condition. The load at the bus of interest is then increased while the load at all other buses are kept constant. The scatter plots of critical points of the PV curve are obtained as a result of modelled uncertainties.

\section{POWER SySTEM MODELLING}

\section{A. Test Network}

In this paper, the modified version of a reduced order equivalent model of NETS-NYPS test system (New England Test System - New York Power System) was used as the simulation network. The diagram of the system is shown in Fig. 1. The test system has 5 areas, 16 generators, and 68 buses. Among these 68 buses, 26 buses are load buses, which are ranked based on their importance for voltage stability. The generators G1-G9 belong to NETS, and G10-G13 are generators of NTPS. G14, G15, and G16 represent the other three neighbouring areas. Among these generators, G9 is equipped with a fast-acting static exciter (IEEE STIA) and power system stabilizer (PSS). Other generators use a slow exciter (IEEE DC1A). All generators are equipped with speed governor systems. Generator G1 includes a GAST speed governor. G3 and G9 comprise IEEEG3 (hydro turbine), and G2-G8, G10-G16 contain IEEEG1 (steam turbine). The synchronous generators are modelled by sixth order models. The transmission lines are represented by the standard $\pi$ equivalent circuit.

There are two types of renewable energy sources (RES) modelled in the test system, which are Type 3 doubly fed induction generators (DFIGs) and Type 4 Full Converter Connected (FCC) units. The wind turbines are represented partly by Type 3 DFIG models and partly by Type 4 FCC models. The photovoltaic (PV) generation, since it is FCC connected, is modelled using Type 4 FCC models as well.

\section{B. Modelling Uncertainties}

The uncertainties of load demand, and PV and wind generation are modelled. The load demand follows a normal distribution, with a standard deviation of 0.033 . The wind generation power output is modelled by a Weibull distribution with a scale parameter of 11.1 and shape parameter of 2.2. The PV power output follows a beta distribution with $\mathrm{a}=13.7$ and $\mathrm{b}=1.3$. After considering the uncertainties in demand and RES generation, the power output of the synchronous generators is given by the optimal power flow.

\section{Load Models}

In this paper, several load models are applied so that the influence of the load models and their parameters on the power system voltage stability can be investigated. The models chosen are most commonly used by the industry, which are static exponential load model and polynomial load model.

The static exponential load model is given by (1) and (2) [20]:

$$
\begin{aligned}
& P=P_{n}\left(\frac{U}{U_{n}}\right)^{k_{p u}} \\
& Q=Q_{n}\left(\frac{U}{U_{n}}\right)^{k_{q u}}
\end{aligned}
$$

Where $\mathrm{P}$ and $\mathrm{Q}$ are the real and reactive power drawn by the load at voltage $U . P_{n}$ and $Q_{n}$ are power drawn at the rated voltage $U_{n}$. The parameters $k_{p u}$ and $k_{q u}$ are the parameters that describe the variation of power caused by the variation of voltage.

The polynomial load model is given by (3) and (4):

$$
\begin{aligned}
& P=P_{n}\left[p_{1}\left(\frac{U}{U_{n}}\right)^{2}+p_{2}\left(\frac{U}{U_{n}}\right)+p_{3}\right] \\
& Q=Q_{n}\left[q_{1}\left(\frac{U}{U_{n}}\right)^{2}+q_{2}\left(\frac{U}{U_{n}}\right)+q_{3}\right]
\end{aligned}
$$


This model is often referred to as 'ZIP model' because it consists of constant impedance (Z), constant current (I), and constant (P) load components. The parameters $p_{1}$ and $q_{1}, p_{2}$ and $q_{2}$, and $p_{3}$ and $q_{3}$ represent the proportion of constant impedance load, constant current load, and constant power load respectively. The sum of parameters $p_{1}, p_{2}$, and $p_{3}$ and $q_{1}, q_{2}$, and $q_{3}$ is 1 p.u.

\section{Load Duration Curve}

In reality, most of the time the system will not operate under a maximum loading factor, and in order to make the load ranking applicable most of the time, the annual system loading condition is taken into consideration. The discrete load duration curve which represents the annual load condition of NETS-NYPS is used where the system maximum demand is chosen to correspond to loading factor 1.339 , as illustrated in Fig. 2.

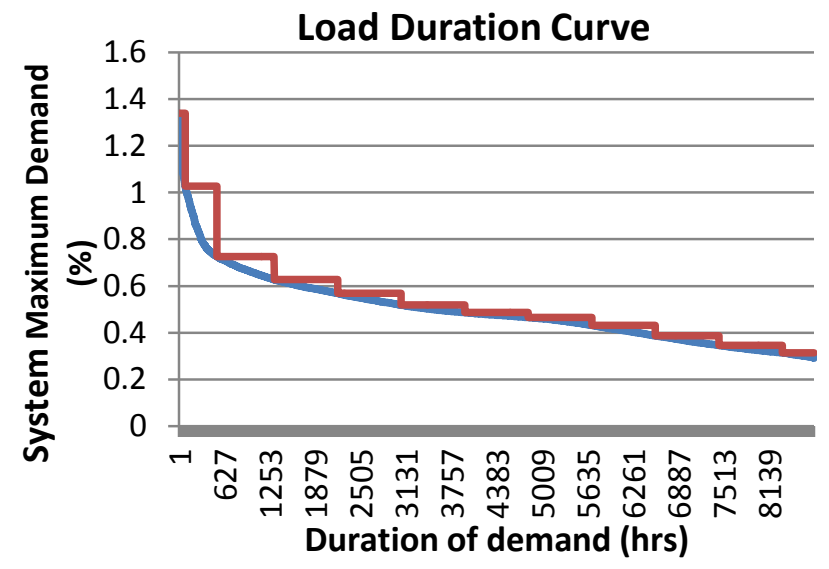

Fig. 2. The annual load duration curve.

The load duration curve of Fig. 2 is divided into 12 time slots as shown in TABLE I, where the maximum system demand (100\%) coincides with the loading factor 1.339.

TABLE I

THE SELECTED 12 OPERATING CONDITIONS

\begin{tabular}{|c|c|c|}
\hline Operating condition & Duration of demand (\%) & Loading factor \\
\hline 1 & 0 & 1.339 \\
\hline 2 & 1 & 1.027 \\
\hline 3 & 6 & 0.726 \\
\hline 4 & 15 & 0.627 \\
\hline 5 & 25 & 0.568 \\
\hline 6 & 35 & 0.518 \\
\hline 7 & 45 & 0.486 \\
\hline 8 & 55 & 0.465 \\
\hline 9 & 65 & 0.432 \\
\hline 10 & 75 & 0.387 \\
\hline 11 & 85 & 0.346 \\
\hline 12 & 95 & 0.314 \\
\hline
\end{tabular}

\section{Methodology}

The approach of this study can be summarized in the following steps: i) Ranking all the loads according to the average voltage difference of each bus between the critical point and initial operating point by simultaneously increasing the loading at all buses. ii) For the five most important loads and five least important loads in the system, obtained from the previous step, investigate the sensitivity of critical point to variation in local load.

\section{A. Load Ranking Based on Criticality for Voltage Collapse}

For each of the loading conditions of the annual load curve, the loadings of each bus are increased simultaneously until the voltage collapse point is reached. The step size of the power increase is adaptive; it will reduce before reaching the stability limit. The initial step size is $0.5 \%$, the maximum step size is $5 \%$, and the minimum step size is $0.01 \%$. The Monte Carlo (MC) method is applied to each loading condition with all the specified uncertainties previously included, and the simulations are repeated 1000 times. The number of simulations is chosen to ensure $99 \%$ confidence that the difference between the true and sampled mean values is less than $1 \%$ of the true mean value, according to equation (5) [21].

$$
\varepsilon_{\bar{x}_{N}}=\frac{\Phi^{-1}\left(1-\frac{\delta}{2}\right) \sqrt{\frac{\sigma^{2}\left(X_{N}\right)}{N}}}{\overline{\bar{X}}_{N}}
$$

In (5), $\Phi^{-1}$ represents the inverse Gaussian conditional probability distribution with a mean of zero and standard deviation of one; $\sigma^{2}$ is the variance of a sample, $\delta$ refers to the desired confidence level, and $X_{N}$ represents a sample of measured outputs containing $\mathrm{N}$ samples. Then, for each loading condition, $1000 \mathrm{MC}$ simulations are performed and the voltage difference between the critical point and the initial operating point is calculated, as shown in Fig. 3.

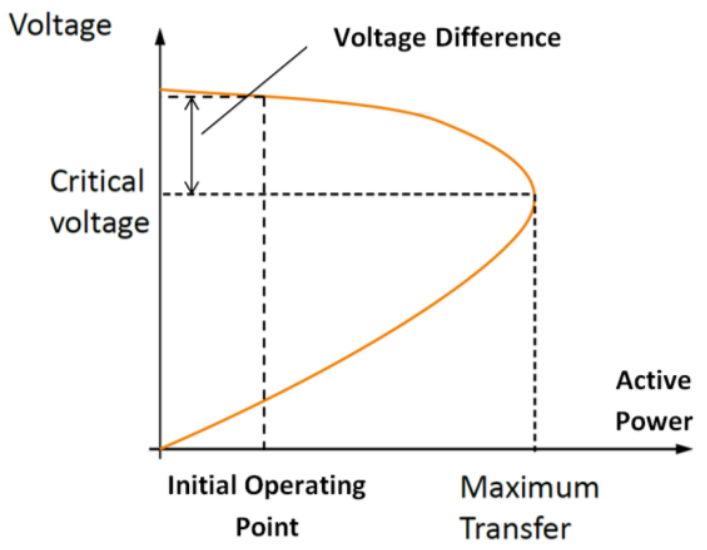

Fig. 3. The voltage difference between the nose point and the initial operating point.

The voltage difference, instead of power difference is used here. This is because that loads are increased simultaneously, when voltage collapses, all loads have been increased for the same percentage, for example, $60 \%$ of the original value. The average and the most probable value of the voltage difference for each load bus are compared and then used for the ranking 
for that loading condition. The load having the largest voltage difference is the most important load as the voltage at that particular bus collapses first. The ranking orders may vary for different loading conditions. Therefore, the final ranking is determined based on cumulative ranking of individual buses for different loading conditions.

\section{B. Identifying the Most Probable Point of Voltage Collapse}

From the ranking obtained from the previous step, the five most important loads and five least important loads are chosen for further analysis. In further studies, only the loading of one bus is increased until the power system collapse point is reached.

In this step, the rated loading is considered. Based on the scatter plot of critical point, the corresponding distribution functions of the voltage and power are obtained and the most probable coordinates of critical points determined.

\section{Changing Load Models}

The sensitivity of voltage collapse point to load modelling is studied by considering constant power, constant impedance and ZIP load model. These load models are most frequently used. According to the International survey on load modelling conducted from 2010 to 2011, when doing steady state power system studies, $84 \%$ of utilities and system operators use constant power load model, and $8 \%$ of them use ZIP load model. When doing dynamic power system studies, for active power, $23 \%$ use constant power load model, $19 \%$ use ZIP load model, for reactive power, $23 \%$ use constant power load model, $22 \%$ use ZIP, and 19\% use constant impedance [20].

\section{RESULTS AND DISCUSSION}

In this study, the MC simulations are carried in MATLAB R2013a. The generated parameter uncertainties are then imported in DIgSILENT PowerFactory 15.2., where voltage stability studies are performed.

\section{A. Load Ranking}

TABLE II

The Average and Most Probable Voltage Drop for the Loading FACTOR OF 0.726

\begin{tabular}{|c|c|c|}
\hline \multicolumn{3}{|c|}{0.726 of the rated load } \\
\hline $\begin{array}{c}\text { bus } \\
\text { number }\end{array}$ & $\begin{array}{c}\text { average voltage } \\
\text { drop (p.u.) }\end{array}$ & $\begin{array}{c}\text { most probable voltage } \\
\text { drop (p.u.) }\end{array}$ \\
\hline 46 & 0.127 & 0.125 \\
\hline 48 & 0.126 & 0.124 \\
\hline 47 & 0.116 & 0.117 \\
\hline 51 & 0.098 & 0.098 \\
\hline 40 & 0.094 & 0.094 \\
\hline 26 & 0.052 & 0.050 \\
\hline 68 & 0.045 & 0.043 \\
\hline 24 & 0.041 & 0.039 \\
\hline 21 & 0.037 & 0.035 \\
\hline 28 & 0.030 & 0.029 \\
\hline
\end{tabular}

As stated in Section III, the PV curve calculation for increasing all the loads simultaneously is done for 12 different operating conditions. Due to limited space, only the results of loading factor 0.726 , and the 5 loads with the largest voltage drop and 5 loads with the least voltage drop are shown above in TABLE II.

As can be seen from the table, the most probable voltage differences are very close to the average voltage differences, and the ranking order is not affected. Therefore, using either of them to rank loads will have the same result. For convenience, the average voltage difference is used for ranking. The result is that bus $46,48,47,51$ and 40 are the most important loads, while bus 26, 68, 24, 21 and 28 are the least important loads. However, the rank of the load changes with the loading conditions. Therefore, TABLE III summarizes the frequency of rank of each of the ten considered loads for 12 considered loading conditions. The number indicates the frequency of particular rank of each load.

TABLE III

THE SUMMARY OF RANKING ORDERS FOR 12 LOADING CONDITIONS

\begin{tabular}{|c|c|c|c|c|c|c|c|c|c|c|}
\hline ranking & 1st & 2nd & 3rd & 4th & 5th & 22nd & 23rd & 24th & 25th & 26th \\
\hline 46 & 10 & & 1 & & & & & & & \\
\hline 48 & 1 & 8 & 2 & & & & & & & \\
\hline 47 & 1 & 3 & 7 & 1 & & & & & & \\
\hline 51 & & & & 10 & & & & & & \\
\hline 40 & & & 1 & & 9 & & & & & \\
\hline 49 & & 1 & & & & & & & & \\
\hline 39 & & & & 1 & & & & & & \\
\hline 45 & & & 1 & & 1 & & & & & \\
\hline 44 & & & & & 2 & & & & & \\
\hline 26 & & & & & & 12 & & & & \\
\hline 68 & & & & & & & 11 & 1 & & \\
\hline 24 & & & & & & & 1 & 10 & 1 & \\
\hline 21 & & & & & & & & & 11 & 1 \\
\hline 28 & & & & & & & & 1 & & 11 \\
\hline
\end{tabular}

It can be seen that for the 5 least important loads, the ranking order does not have obvious change. Similarly, for the 5 most important loads, although there is some variation in load rank for different loading conditions, the overall ranking remains the same, i.e., the 5 most important load buses are 46, 48, 47, 51 and 40.

\section{B. Sensitivity of Critical Point to Parameter Uncertainty}

Fig. 4 below shows the scatter plot of critical point for ten selected buses at the rated loading. It can be seen that the important buses are generally located at the left of the figure, i.e., the increase in load that this bus can tolerate before the voltage collapse is the smallest. Bus 51 is an exception to this because in the test system considered, a source of reactive power is connected to bus 51 which supports its voltage following load increase. 


\section{ACCEPTED VERSION OF THE PAPER}

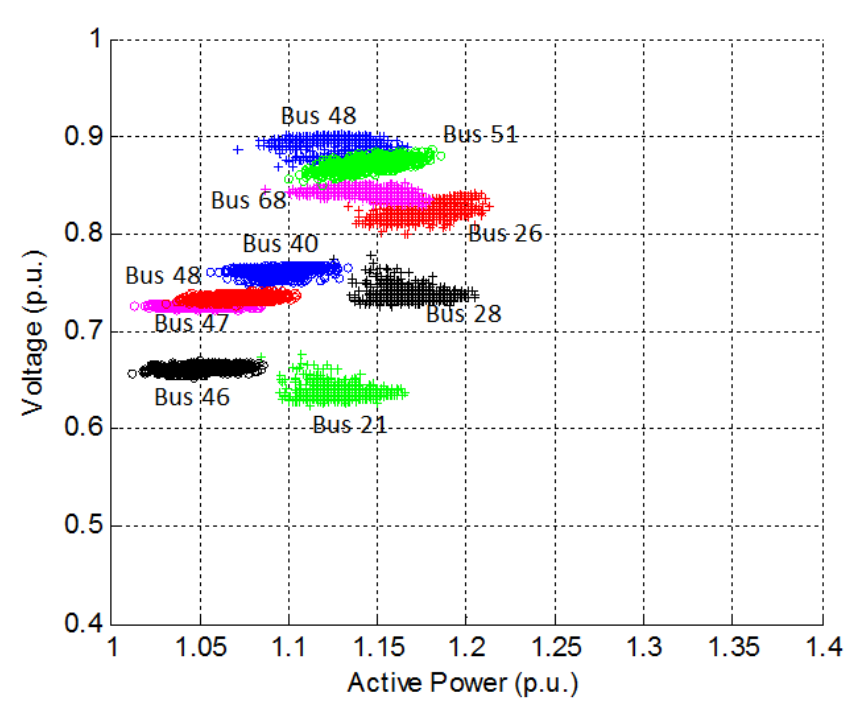

Fig. 4. Scatter plot of critical point for ten selected buses at rated loading factor.

The pdfs of critical point locations of all buses are produced for both voltage and power in order to determine the most probable point of voltage collapse. This is illustrated, as an example, in Fig. 5 for bus 51.

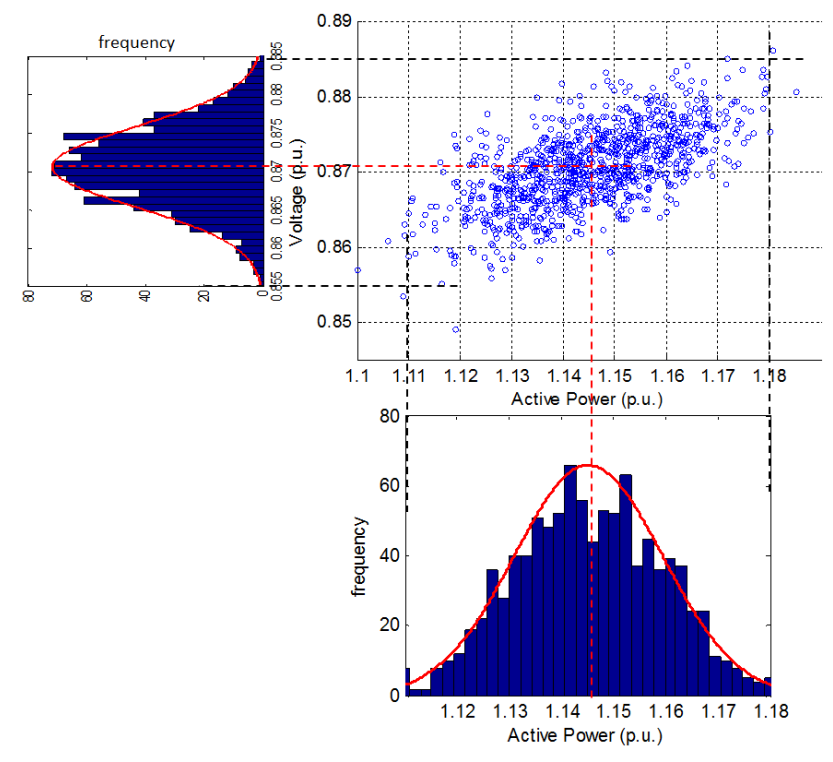

Fig. 5. The pdf of voltage and power of bus 51 .

From Fig. 5 it can be seen that the most probable point of voltage collapse is the point with coordinates $\mathrm{P}=1.145$ p.u. and $\mathrm{V}=0.871 \mathrm{p} . \mathrm{u}$. The most probable voltage collapse points will be used in the study of the influence of load models on voltage stability.

\section{The influence of Load Models}

All the load models are then changed to be constant impedance load models and ZIP load models. The parameters of ZIP load model are as follows: $p_{1}=0.827, p_{2}=-$ $0.049, p_{3}=0.222, q_{1}=14.14, q_{2}=-24.838, q_{3}=11.696 \quad$ [22]. The nose points are obtained in the same way as in the previous step. The nose point results are shown in Fig. 6 below.

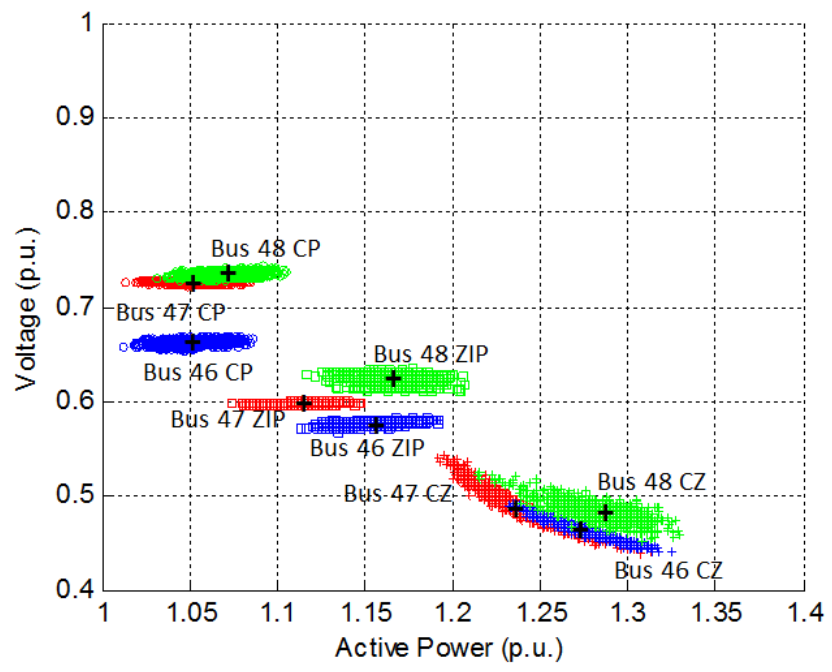

Fig. 6. Comparison of nose point results for constant power, constant impedance, and ZIP load model.

In Fig. 6, $\mathrm{CP}$ denotes the constant power load model, $\mathrm{CZ}$ represents constant impedance load model, and ZIP stands for the ZIP load model. It can be seen that the critical point locations of all buses have changed. The loads generally become less prone to voltage collapse, i.e., they were able to tolerate larger increase in load, after the load model was changed from constant power to ZIP and constant impedance load model. When looking at the distribution of the voltage collapse points, it can be found that the distribution for constant impedance load model is the most scattered while the distribution for constant power load model is the most concentrated. Therefore it can be concluded that the constant impedance load model is most sensitive to uncertainties, while the constant power load model is least sensitive to uncertainties.

TABLE IV shows the coordinates $(\mathrm{P}, \mathrm{V})$ of most probable point of collapse for each of the three loads and for three different load models. The corresponding most probable points are marked in Fig. 6 by plus signs. The table also shows relative change in $\mathrm{P}$ and $\mathrm{V}$ coordinate separately compared to original location, which is the one obtained with constant power load model.

\section{TABLE IV}

COMPARISON OF COORDINATES OF MOST PROBABLE VOlTAGE COLLAPSE POINTS

\begin{tabular}{|c|c|c|c|c|c|c|c|c|c|c|}
$\begin{array}{c}\text { Load } \\
\text { models }\end{array}$ & $\begin{array}{c}\text { Constant } \\
\text { power load } \\
\text { model }\end{array}$ & \multicolumn{6}{|c|}{$\begin{array}{c}\text { Constant impedance load } \\
\text { model }\end{array}$} & \multicolumn{5}{|c|}{ ZIP load model } \\
\hline Axies & $\mathrm{P}$ & $\mathrm{V}$ & $\mathrm{P}$ & $\Delta \mathrm{P}$ & $\mathrm{V}$ & $\Delta \mathrm{V}$ & $\mathrm{P}$ & $\Delta \mathrm{P}$ & $\mathrm{V}$ & $\Delta \mathrm{V}$ \\
\hline bus 46 & 1.051 & 0.662 & 1.273 & 0.222 & 0.465 & -0.197 & 1.159 & 0.108 & 0.574 & -0.088 \\
\hline bus 48 & 1.071 & 0.737 & 1.282 & 0.211 & 0.479 & -0.258 & 1.169 & 0.098 & 0.624 & -0.113 \\
\hline bus 47 & 1.054 & 0.726 & 1.238 & 0.184 & 0.483 & -0.243 & 1.119 & 0.065 & 0.594 & -0.132 \\
\hline
\end{tabular}

All values in p.u.

\section{CONCLUSIONS}

This paper ranks power system loads for voltage stability considering power system uncertainties and compares the 


\section{ACCEPTED VERSION OF THE PAPER}

results for different load models. The PV curve is the method used to identify the important loads in a power network. The uncertainties of load variation, wind power, and solar power are taken into account to truly reflect the stochastic behaviour of the power system. In order to consider different operating points of the system during the year, 12 different loading conditions selected from the annual loading curve are used. All loads are initially modelled using constant power load model. The buses which are the most and the least sensitive in terms of voltage stability to system uncertainties are identified first. Following that, the load model at critical buses is varied to establish the importance of load modelling for voltage stability in the network. The results confirm that the susceptibility of the network to voltage collapse increases as the load model changes from constant impedance load model, to ZIP and constant power load model, i.e., the more stiff the load is the less voltage stable the network will be. It was also found that the variation in critical point with system uncertainties increases with modelled load flexibility. The stiffer the load model is (constant power) the less sensitive the critical point is to system uncertainties.

\section{REFERENCES}

[1] C. W. Taylor and D. C. Erickson, "Recording and analyzing the July 2 cascading outage [Western USA power system]," Computer Applications in Power, IEEE, vol. 10, pp. 26-30, 1997.

[2] L. Vargas, V. H. Quintana, and R. Miranda D, "Voltage collapse scenario in the Chilean interconnected system," Power Systems, IEEE Transactions on, vol. 14, pp. 1415-1421, 1999.

[3] M. Adibi, "Analysis of the Power Blackout of June 8, 1995 in the Israel Electric Corporation," in Power System Restoration:Methodologies \&amp; Implementation Strategies, ed: Wiley-IEEE Press, 2000, pp. 432-437. [4] D. N. Kosterev, C. W. Taylor, and W. A. Mittelstadt, "Model validation for the August 10, 1996 WSCC system outage," Power Systems, IEEE Transactions on, vol. 14, pp. 967-979, 1999.

[5] P. Kundur, Power System Stability and Control, 2nd ed. vol. 1. New York: McGraw-Hill, 1994.

[6] F. Capitanescu and T. Van Cutsem, "Preventive control of voltage security margins: a multicontingency sensitivity-based approach," Power Systems, IEEE Transactions on, vol. 17, pp. 358-364, 2002.

[7] H. Nallan and P. Rastgoufard, "Computational voltage stability assessment of large-scale power systems," Electric power systems research, vol. 38, pp. 177-181, 1996.

[8] L. Braz, C. Castro, and C. Murati, "A critical evaluation of step size optimization based load flow methods," Power Systems, IEEE Transactions on, vol. 15, pp. 202-207, 2000.

[9] S. Greene, I. Dobson, and F. L. Alvarado, "Sensitivity of the loading margin to voltage collapse with respect to arbitrary parameters," Power Systems, IEEE Transactions on, vol. 12, pp. 262-272, 1997.
[10] R. B. a. R. N. Allan, Reliability Evaluation of Power Systems, 2nd ed. New York: Plenum, 1996.

[11] R. B. a. W. Li, Reliability Assessment of Electric Power Systems Using Monte Carlo Methods. New York: Plenum, 1994.

[12] R. Billinton and S. Aboreshaid, "Voltage stability considerations in composite power system reliability evaluation," Power Systems, IEEE Transactions on, vol. 13, pp. 655-660, 1998.

[13] S. Aboreshaid and R. Billinton, "Probabilistic evaluation of voltage stability," Power Systems, IEEE Transactions on, vol. 14, pp. 342348, 1999.

[14] H. Wan, J. D. McCalley, and V. Vittal, "Risk based voltage security assessment," Power Systems, IEEE Transactions on, vol. 15, pp. 1247-1254, 2000.

[15] G. M. Huang and N.-K. C. Nair, "Voltage stability constrained load curtailment procedure to evaluate power system reliability measures," in Power Engineering Society Winter Meeting, 2002. IEEE, 2002, pp. 761-765.

[16] K. Morison, H. Hamadani, and L. Wang, "Practical issues in load modeling for voltage stability studies," in Power Engineering Society General Meeting, 2003, IEEE, 2003, pp. 1392-1397.

[17] C.-J. Lin, Y.-T. Chen, C.-Y. Chiou, C.-H. Huang, H.-D. Chiang, J.-C. Wang, and L. Fekih-Ahmed, "Dynamic load models in power systems using the measurement approach," Power Systems, IEEE Transactions on, vol. 8, pp. 309-315, 1993.

[18] M. M. Begovic and A. G. Phadke, "Dynamic simulation of voltage collapse," Power Systems, IEEE Transactions on, vol. 5, pp. 1529$1534,1990$.

[19] J. Milanović, I. A. Hiskens, and V. Maslennikov, "Ranking loads in power systems-comparison of different approaches," Power Systems, IEEE Transactions on, vol. 14, pp. 614-619, 1999.

[20] W. C4.605, "Modelling and Aggregation of Loads in Flexible Power Networks," CIGREFebruary 20142014.

[21] J. L. Rueda, D. G. Colomé, and I. Erlich, "Assessment and enhancement of small signal stability considering uncertainties," Power Systems, IEEE Transactions on, vol. 24, pp. 198-207, 2009.

[22] J. Milanović and I. Hiskens, "Oscillatory interaction between synchronous generator and local voltage-dependent load," in Generation, Transmission and Distribution, IEE Proceedings-, 1995, pp. 473-480.

Yue Zhu (S'14) received a BEng degree in Electrical and Electronic Engineering from the University of Manchester, Manchester, U.K. and North China Electric Power University, Baoding, China, in 2015. He is currently working towards a Ph.D. degree at the University of Manchester.

Jovica V. Milanović (M'95-SM'98-F'10) received Dipl.Ing. and M.Sc. degrees from the University of Belgrade, Belgrade, Yugoslavia, a Ph.D. degree from the University of Newcastle, Newcastle, Australia, and a D.Sc. degree from the University of Manchester, Manchester, U.K., all in Electrical Engineering. He is currently a Professor of Electrical Power Engineering, Deputy Head of the School and Director of External Affairs in the School of Electrical and Electronic Engineering at the University of Manchester, Manchester, U.K., a Visiting Professor at the University of Novi Sad, Novi Sad, Serbia and University of Belgrade, Belgrade, Serbia and a Conjoint Professor at the University of Newcastle, Newcastle, Australia. 